\title{
Legalidad y prescripción frente a la investigación de crímenes de lesa humanidad en Colombia*
}

\begin{abstract}
Alfonso Daza González
Recibido: 20 de marzo de 2013 • Revisado: 20 de abril de 2013 • Aprobado: 6 de mayo de 2013

\section{Resumen}

Se analiza en este artículo la tensión que existe entre el principio de legalidad y la prescripción de la acción penal en Colombia, y el deber de investigar y juzgar los delitos de lesa humanidad que impone el derecho internacional.
\end{abstract}

Palabras clave: legalidad, prescripción, investigación criminal, enjuiciamiento, crímenes de lesa humanidad.

\section{LEGALITY AND STATUTE OF LIMITATION WITH REGARDS TO THE inVESTIgATION OF CRIMES Against humanity in Colombia}

\begin{abstract}
This article analyzes the tension existing between the principle of legality and the statute of limitation of the criminal action in Colombia, and the duty to investigate and prosecute crimes against humanity under international law.
\end{abstract}

"Artículo de reflexión producto del proyecto de investigación que, como tesina para optar al título de doctor en Derecho, el autor defendió en la Universidad Alfonso X El Sabio (Madrid, España) el 17 de septiembre de 2010; fue aprobado y al autor se le otorgó el Diploma de Estudios Avanzados.

* Abogado, especialista y magíster en Derecho Penal y Criminología por la Universidad Libre. Máster en Derechos Humanos, Estado de Derecho y Democracia en Iberoamérica por la Universidad de Alcalá, España. Doctor en Derecho por la Universidad Externado de Colombia. Candidato a un segundo doctorado en Derecho por la Universidad Alfonso X El Sabio (Madrid, España). Docente investigador de la Facultad de Derecho del grupo Derecho Penal, Derechos Humanos y Derecho Disciplinario de la Universidad Libre. Correo electrónico: alfonso.daza@unilibre.edu.co, adazaabogado@hotmail.com 
Keywords: legality, statute of limitation, criminal investigation, prosecution, crimes against humanity.

\section{LEgALIDADE E PRESCRIÇÃo PERANTE A INVESTIGAÇÃo DE CRIMES DE LESA HUMANIDADE Na Colômbia}

\section{Resumo}

Analisa-se neste artigo a tensão existente entre o princípio da legalidade e a prescrição da ação penal na Colômbia, e o dever de pesquisar e julgar os crimes de lesa humanidade que impõe o direito internacional.

Palavras chave: legalidade, prescriçãa, investigação criminal, julgamento, crimes de lesa humanidade.

\section{Introducción}

En toda investigación, en la medida en que se avanza en la recolección de información, en el agotamiento del estado del arte y en el análisis teórico del problema para tratar, se delimita y perfila el problema de estudio hasta que alcanza una dimensión adecuada a los propósitos del investigador.

En este caso, el título inicial de la investigación era "El deber de investigar y de juzgar los delitos de genocidio, lesa humanidad y los crímenes de guerra, frente al principio de irretroactividad de la ley penal y la prescripción de la acción penal en Colombia". En este planteamiento inicial se esperaba determinar si existía o no tensión jurídica entre el deber de investigar y juzgar los delitos de genocidio, lesa humanidad y los crímenes de guerra, y los principios de irretroactividad de la ley y prescripción de la acción penal en Colombia. Este primer acercamiento, sin embargo, adolecía de un obstáculo fundamental: el marco jurídico, dentro del cual habría de tratarse el tema de los delitos de genocidio, lesa humanidad y crímenes de guerra, no estaba definido con suficiencia y por lo tanto era demasiado amplio, abarcando la totalidad de los sistemas de protección de derechos humanos en el mundo, el derecho penal internacional e incluso el derecho internacional humanitario. 
Por esta razón, se observó la necesidad de delimitar el ámbito jurídico dentro del cual habrían de analizarse esta clase de delitos y, en particular, el deber de los Estados de investigarlos y de juzgarlos. Por ser el sistema dentro del cual se encuentra inscrito el Estado colombiano y el que con mayor profundidad ha encarado la determinación de distintas violaciones a los derechos humanos cometidas dentro del territorio nacional, se prefirió el sistema interamericano de derechos humanos para tal propósito. En esa decisión influyó también la nutrida jurisprudencia que los órganos del sistema han desarrollado a propósito del deber estatal de investigar y de juzgar de manera seria, efectiva e imparcial las violaciones a los derechos y libertades consignados en la Convención Americana sobre Derechos Humanos.

Sin embargo, un segundo escollo se presentó en el hecho de encontrarse, en dicha jurisprudencia, continuas referencias a los crímenes de lesa humanidad a secas, sin analizar el genocidio y los crímenes de guerra como delitos autónomos de aquellos. En efecto, en el sistema interamericano suelen considerar el genocidio y los crímenes de guerra como delitos contra la humanidad, y los crímenes de lesa humanidad, en general, como delitos que pueden cometerse en tiempos de guerra o en tiempos de paz, indistintamente. Por ello, y con el fin de utilizar una acepción amplia del concepto, se decidió instaurar como objeto de estudio el deber de investigar y juzgar los crímenes de lesa humanidad que impone el sistema interamericano de derechos humanos.

Además, el análisis de la información recolectada permitió inferir de entrada las fuertes tensiones jurídicas entre los principios de irretroactividad de la ley y prescripción de la acción penal, por una parte, y el deber de investigar y juzgar los crímenes de lesa humanidad en el Sistema Interamericano de Derechos Humanos, por otra. Por ello, se decidió fijar como objetivo general de la investigación, ya no determinar si existe una tensión jurídica entre uno y otro extremo, sino cómo se resuelve esta tensión evidente desde un principio. En consecuencia, y de acuerdo con lo antes reseñado, el problema de investigación se fijó así: ¿Cómo se resuelve la tensión que existe entre los principios de irretroactividad de la ley y prescripción de la acción penal en Colombia, y el deber de investigar y juzgar los delitos de lesa humanidad en el marco del Sistema Interamericano de Derechos Humanos?

Ahora bien, un análisis cuidadoso de la jurisprudencia y doctrina de los órganos del Sistema Interamericano de Derechos Humanos permitió constatar que, si bien estos órganos han desarrollado un corpus iuris importante en lo relativo al deber internacional de investigar y juzgar los hechos constitutivos de violaciones a los derechos humanos, sus decisiones con respecto a los delitos de lesa humanidad 
son bastante limitadas. Ello es así porque las facultades otorgadas a estos órganos por los tratados del sistema regional son únicamente consultiva (interpretación de un tratado), cautelar (protección urgente de personas en situación de riesgo) y contenciosa (determinación de violación a los derechos contenidos en las cartas interamericanas y de la responsabilidad correlativa del Estado), mas no cuentan con la competencia para calificar si en un caso concreto una conducta delictiva constituye un delito de lesa humanidad y quiénes fueron sus responsables. En muy contadas ocasiones, la Corte Interamericana ha determinado que las violaciones de derechos humanos bajo su análisis constituyen crímenes de lesa humanidad (Corte Interamericana de Derechos Humanos, 2006b, párr. 225; 2006a, párr. 99), pero, como afirma en un caso reciente, lo ha hecho con un propósito pedagógico, por la necesidad de interpretar el derecho internacional de los derechos humanos en su relación con otras ramas del derecho internacional público, como el derecho penal internacional o el derecho internacional humanitario, o con el simple fin de establecer la responsabilidad agravada del Estado o subrayar la urgencia del deber de investigar y juzgar tales conductas (Corte Interamericana de Derechos Humanos, 2010, párr. 42).

Por lo tanto, se hizo necesario abrir de nuevo el campo de investigación, de forma que el análisis de la investigación y el juzgamiento de conductas constitutivas de crímenes de lesa humanidad en Colombia se realizara a partir del derecho internacional de los derechos humanos - con sus distintos sistemas de protección-e igualmente a partir del derecho penal internacional y del derecho internacional humanitario. De esta forma, se espera mayor alcance y profundidad en el examen de las tensiones jurídicas presentes en los procesos judiciales colombianos para el juzgamiento de tales conductas atroces.

Finalmente, dado que el principio de irretroactividad de la ley penal se inscribe en el principio más general e incluyente de la legalidad, se ha preferido esta última expresión para designar la prohibición de calificar una conducta como delito sin una ley previa que la conmine, y de aplicar una sanción que no está prevista en la ley con anterioridad. La legalidad se asume aquí como un principio rector del derecho penal sustantivo y procesal y, asimismo, como una garantía judicial en cabeza del procesado. El principio de la prescripción de la acción penal, por su lado, permanece como parte del problema de investigación por resolver, pues la determinación de delitos imprescriptibles en el derecho internacional, y su adecuación al ordenamiento interno, plantea serios debates que abordaremos en su momento. 
En ese orden de ideas, el problema de investigación se ha reformulado con la siguiente pregunta: ¿Cómo se resuelve la tensión que existe entre los principios de legalidad y prescripción de la acción penal en Colombia, y el deber de investigar y juzgar los delitos de lesa humanidad que impone el derecho internacional?

\section{Legalidad, irretroactividad y prescripción de la acción penal en la investigación y juzgamiento de crímenes de lesa humanidad}

En esta investigación, como su título lo indica, se pretende determinar cómo se resuelve la tensión existente entre los principios de irretroactividad de la ley y prescripción de la acción penal en Colombia, por una parte, y el deber de investigar y juzgar los delitos de lesa humanidad que impone el derecho internacional de los derechos humanos y el derecho penal internacional, por otra.

De un lado, el orden jurídico interno prescribe que la ley penal sustancial y procesal se aplicará "única y exclusivamente para la investigación y el juzgamiento de los delitos cometidos con posterioridad a su vigencia" (Ley 906, 2004). Esto implica que la ley penal no puede aplicarse a la persecución de conductas delictivas realizadas con anterioridad a su entrada en vigencia o, dicho de otra forma, que no puede ejercerse de manera retroactiva. A este axioma fundamental se le conoce como principio de irretroactividad y, según se encuentra estipulado en la norma, constituye parte integral del principio de legalidad. Este último ordena que "nadie podrá ser juzgado sino conforme a leyes preexistentes al acto que se le imputa, ante juez o tribunal competente y con observancia de la plenitud de las formas propias de cada juicio" (Constitución Política de Colombia, 1991, art. 29, inc. 2; Ley 599, 2000, art. 6, inc. 1; Ley 906, 2004, art. 6, inc. 1).

Adicionalmente, la legislación colombiana admite la prescripción de la acción penal como una de las formas de su extinción (Ley 599, 2000, art. 82, num. 4). La prescripción de la acción penal indica que una vez transcurrido un periodo desde la comisión de una conducta punible sin que contra esta se haya iniciado formalmente una investigación penal, el Estado pierde la oportunidad de perseguirla. En Colombia, este periodo se estableció en un tiempo igual al máximo de la pena fijada en la ley, si fuere privativa de la libertad, pero en ningún caso puede ser inferior a cinco años ni exceder de veinte, salvo lo dispuesto para las conductas punibles de genocidio, desaparición forzada, tortura y desplazamiento forzado, cuya 
prescripción fue fijada en treinta años (Ley 599, 2000, art. 83). Una regulación completa del fenómeno de la prescripción se encuentra claramente definida en la ley penal colombiana.

Ahora bien, una hermenéutica sistemática de las normas constitucionales exige que las disposiciones contenidas en la Carta Política se interpreten en conjunto, con el objeto esencial de brindar al sistema jurídico coherencia y estabilidad. Siguiendo este parámetro, las disposiciones antes aludidas deben interpretarse a la luz de lo dispuesto en los artículos 93 y 94 superiores, que ordenan la prevalencia en el orden interno de los tratados y convenios internacionales de derechos humanos ratificados por el Congreso de la República, el deber de interpretar los derechos y deberes constitucionales de conformidad con dichos convenios y tratados, y la protección que merecen otros derechos inherentes a la persona humana aun cuando estos no estén expresamente reconocidos (Constitución Política de Colombia, 1991, art. 93, incs. 1 y 2 , y art. 94).

En este orden de ideas, resulta imperativo que los principios de irretroactividad de la ley penal y prescripción de la acción penal se interpreten de acuerdo y contrastados con las disposiciones fijadas en los tratados y convenios internacionales de derechos humanos aprobados y ratificados en Colombia por el poder legislativo.

En este ejercicio interpretativo se advierte de entrada que los sistemas de protección de los derechos humanos (universal e interamericano) se establecen para el Estado colombiano como obligaciones que, una vez puestas en marcha, entran en colisión con los deberes fijados por el legislador interno. El derecho internacional de los derechos humanos exige del Estado la investigación seria e imparcial de conductas constitutivas de violaciones a los derechos humanos, el derecho penal internacional, de los delitos llamados de lesa humanidad, y el Estado, al acatar estas exigencias, adelanta la investigación y el posterior juzgamiento de dichas violaciones a partir de leyes que en el momento de cometerse los delitos no estaban vigentes, en detrimento del principio de irretroactividad de la ley penal. Incluso, en cumplimiento de este deber de investigar se persiguen conductas cuya acción penal se encuentra prescrita, en detrimento del fenómeno de la prescripción de la acción penal.

Esta situación es paradójica si se tiene en cuenta que la misma Convención Americana sobre Derechos Humanos, aprobada en Colombia, ordena que "nadie puede ser condenado por acciones u omisiones que en el momento de cometerse no fueran delictivos según el derecho aplicable" (Convención Americana sobre Derechos Humanos, 1969). Este reconocimiento del principio de irretroactividad 
de la ley penal es hallable también en las cartas internacionales que reconocen derechos humanos en los sistemas universal, europeo y africano, así como en el derecho internacional humanitario y el derecho penal internacional (Declaración Universal de Derechos Humanos, 1948, art. 11.2; Convenio Europeo para la Protección de los Derechos Humanos y de las Libertades Fundamentales, 1950, art. 7.1; Pacto Internacional de Derechos Civiles y Políticos, 1966, art. 15.1; Protocolo I adicional a los Convenios de Ginebra, 1977a, art. 75.4.c; Protocolo II adicional a los Convenios de Ginebra, 1977b, art. 6.2.c; Carta Africana sobre los Derechos Humanos y de los Pueblos, 1981, art. 7.2; Convención sobre los Derechos del Niño, 1989, art. 40.2.a; Estatuto de la Corte Penal Internacional, 1998, art. 22.1; Carta de los Derechos Fundamentales de la Unión Europea, 2000, art. 49.1).

Puesta en evidencia la tensión existente entre los principios de irretroactividad de la ley y prescripción de la acción penal en Colombia y el deber de perseguir los delitos de lesa humanidad que imponen los tratados y las decisiones vinculantes de los órganos de protección de los derechos humanos, esta investigación se propone dilucidar cómo se resuelve dicha tensión en casos concretos, si dando aplicación a la irretroactividad de la ley y a la prescripción de la acción penal en atención a los derechos fundamentales y a los principios generales del derecho, o si cediendo el paso a la retroactividad de ella y a la imprescriptibilidad de los delitos en aras de atender a los requerimientos de instancias internacionales y así evitar la impunidad de crímenes de la más alta gravedad.

Las discusiones alrededor de esta fuerte tensión hacen parte de la preocupación constante de teóricos y pragmáticos del derecho por perfeccionar la estructura del sistema jurídico y, de esa manera, darle un rumbo diferente a la realidad social. En efecto, si se comprenden mejor las estructuras que gobiernan la vida en sociedad, será posible conducirla al avance y al progreso. Si se entiende el sustento jurídico de los principios rectores de la ley penal y el fundamento jurídico y acaso político del deber de investigar y juzgar los delitos de lesa humanidad, y en concreto las tensiones presentes entre ambos extremos, podrá determinarse, por ejemplo, si esta obligación internacional constituye una potente herramienta de cambio social o una deleznable regresión a nivel normativo que desestabiliza el sistema jurídico.

No se trata en absoluto de una tensión aparente sino de un choque de concepciones jurídicas y acaso políticas que se expresa en diferentes ámbitos sociales, siendo el más concreto de ellos el proceso judicial. Es común observar fuertes resistencias en los procesos penales internos adelantados en virtud del cumplimiento de una decisión proferida por un órgano del Sistema Interamericano. Por una parte, las 
víctimas y sus abogados les recuerdan a los jueces la obligación internacional de investigar y de juzgar los delitos de lesa humanidad sin importar el momento en el que se cometieron y con base en la consideración de estos delitos como imprescriptibles; y por otra parte, los agresores y sus defensores esgrimen su derecho legítimo a ser investigados y si es el caso juzgados de acuerdo con normas sustanciales y procesales vigentes en el momento de comisión de los hechos, y a ser amparados, si se presenta la circunstancia, por el fenómeno de la prescripción de la acción penal.

Aunque los delitos cuyo deber de investigar se impone revisten una enorme gravedad, es de gran importancia también para los derechos de los procesados y aún para la estabilidad jurídica el respeto a los principios de irretroactividad de la ley y prescripción de la acción penal. Dada la inobservancia a estas normas rectoras, se llegó al extremo de, por ejemplo, crear tipos penales con su respectiva sanción para la represión específica de un hecho en particular, por supuesto ya acaecido, o se dejaron sin efectos leyes del pasado que ponían punto final al debate sobre su posible enjuiciamiento, para abrir de nuevo los procesos. Todo ello ha conducido, en no pocas ocasiones, a juicios penales carentes de imparcialidad e independencia, sin garantía alguna, en los que se privilegian criterios de conveniencia política en menoscabo de derechos fundamentales. Y desde el punto de vista de la seguridad jurídica, no solo se vulnera ese pilar del Estado de derecho que constituye el principio de legalidad, sino que el proceso penal se convierte en una mise en scène de un castigo decidido de antemano.

No obstante los delitos de lesa humanidad en Colombia son de vieja data y permean las más de cuatro décadas de conflicto armado interno, las investigaciones y juicios de estos crímenes son bastante recientes y la jurisprudencia hasta ahora empieza a consolidarse. En esta labor cabe destacar el esfuerzo que realizan la Unidad Nacional de Derechos Humanos y Derecho Internacional Humanitario de la Fiscalía General de la Nación, la Procuraduría General de la Nación, los juzgados especializados y la Sala Penal de la Corte Suprema de Justicia. A estos esfuerzos cabe sumar las iniciativas de la sociedad civil, agrupada en organizaciones sociales y de derechos humanos, en partidos políticos, en centros de estudio y en asociaciones profesionales, cuya preocupación por la vigencia y el respeto a los derechos humanos ayuda a situar en la agenda pública la necesidad de encarar las atrocidades cometidas en el pasado. Finalmente, es notable la colaboración que prestan las agencias de cooperación internacional y la comunidad internacional en general, quienes contribuyen desde el punto de vista financiero, técnico y funcional para la consolidación de una cultura de derechos humanos en el país. 
En todo caso, son muchos los retos por afrontar, pues los juicios penales son pocos y la impunidad es alarmante, y en las pocas causas adelantadas son evidentes los problemas jurídicos, acaso políticos, que plantea el juzgamiento de este tipo de conductas, así como la respuesta insuficiente de los operadores jurídicos a estos interrogantes. Es común, por ejemplo, que se ignoren los avances de la normativa y la doctrina internacional sobre delitos internacionales, y que los jueces sigan aplicando las normas internas a conductas de relevancia internacional que merecen un reproche mayor al impuesto. Esta situación se ve agravada porque muchos de los delitos perseguidos se cometieron con anterioridad a la entrada en vigencia del nuevo Código Penal e incluso de la Constitución Política. Es usual también que se empleen mixturas de derecho interno y derecho internacional que son en ocasiones aceptables y en otras inviables jurídicamente. En otras ocasiones se intentó también juzgar este tipo de delitos en la jurisdicción penal militar, a pesar de la prohibición que existe en tal sentido en el derecho nacional y supranacional, intentando enmarcar los crímenes de la Fuerza Pública en un contexto de guerra en el que ciertos costos deben asumirse. Finalmente, la imputación de tipos penales y la adjudicación de penas ha sido bastante problemática, pues es frecuente la ausencia de una norma legal que cubra estas exigencias del procedimiento penal.

Hace falta entonces desnudar las tensiones presentes en esta especie de combate que se libra dentro del proceso penal colombiano y, en la medida de lo posible, brindar una herramienta teórica a juristas y operadores judiciales tendiente a resolverlo en un caso particular. Al intentar resolver esta tensión, se pretende ofrecer una base para adelantar la investigación y juzgamiento penal de los más graves crímenes, sin sacrificar garantías fundamentales ni principios rectores del procedimiento o, al menos, con plena consciencia de las consecuencias que acarrea su sacrificio. Así se espera aportar un trabajo que sirva a un doble propósito: evitar la impunidad de crímenes atroces y, a un tiempo, mantener incólume la seguridad jurídica.

Desde el punto de vista metodológico, esta es una investigación de dogmática jurídica, teniendo en cuenta que el objeto de análisis que contempla es la tensión hallable entre las obligaciones internacionales del Estado en los sistemas de protección internacional y las normas nacionales que reconocen principios y derechos fundamentales. Este problema se abordará desde el texto constitucional colombiano, el derecho comparado y, sobre todo, desde el derecho internacional de los derechos humanos y el derecho penal internacional, y la incorporación de estos al orden interno por vía del bloque de constitucionalidad. 


\section{Conclusiones}

La tensión entre los principios de legalidad y prescripción de la acción penal, por una parte, y la persecución -retroactiva- de crímenes de lesa humanidad -imprescriptibles-, por otra, están presentes no solo en la justicia colombiana actual, sino a lo largo de la historia del derecho penal internacional. La configuración de cortes penales de carácter internacional para el juzgamiento de crímenes de la más alta gravedad cometidos con anterioridad a la entrada en vigencia de las leyes que habrán de juzgarlos, a veces con décadas de anterioridad, ha tenido que enfrentarse necesariamente a este problema.

Por una parte, los procesados alegan su derecho a ser juzgados de conformidad con leyes preexistentes a los hechos que se les imputan, argumentando con certeza que el principio de legalidad es una garantía antiquísima de cuyo respeto depende la seguridad jurídica y la estabilidad del Estado de derecho, y agregan que la prescripción de la acción penal es un principio rector del procedimiento y una garantía de que la persecución no se extenderá indefinidamente en el tiempo. Por otro lado, quienes procuran el juzgamiento de este tipo de crímenes se acogen a una doctrina internacional ya muy consolidada, según la cual los delitos de lesa humanidad pueden investigarse de manera retroactiva y su acción penal es imprescriptible, tomando como base la gravedad del delito, su impacto sobre el género humano, la necesidad de no dejarlo impune, e incluso el derecho de las víctimas a que se haga justicia y a superar su dolor.

No cabe duda de que las directrices internacionales, tanto las derivadas del derecho convencional como del derecho consuetudinario, a pesar del extendido reconocimiento del principio de legalidad, son proclives a apoyar esta segunda postura, a saber, la necesidad de juzgar los crímenes de lesa humanidad en cualquier tiempo y a partir de leyes aplicadas de manera retroactiva. Después de la segunda guerra mundial se consolidó en la comunidad internacional un cuerpo normativo y jurisprudencial que aboga por el castigo a toda costa de los crímenes más graves, que prohíbe las leyes de amnistía o punto final, que fija estándares muy altos de verdad, justicia y reparación para las víctimas, que monitorea los mecanismos internos de justicia transicional y, en fin, que impone serias obligaciones a los Estados en materia de derechos humanos.

Dentro de estas obligaciones destaca el deber internacional de perseguir y, si es el caso, condenar a los culpables de crímenes de lesa humanidad, pues se entiende que estos delitos constituyen una afrenta gravísima a la conciencia humana. Y de 
hecho así es: la historia ha demostrado que el genocidio, la esclavitud, la tortura, la violación o el encarcelamiento son conductas atroces que ofenden la dignidad humana y exigen una respuesta desde el ámbito punitivo. Pero la reacción a estas conductas debe guardar ciertos límites. No es posible, por ejemplo, restaurar el orden quebrado por el delito, por grave que este sea, a través de la exclusión del delincuente de las garantías o beneficios de ese mismo orden. Nos referimos puntualmente a los derechos del procesado, cuyo reconocimiento jurídico se remonta a las primeras manifestaciones de la organización social. El principio de legalidad, enunciado en la fórmula romana nullum crimen sine lege, no solo es una de las primeras garantías que se conocen, sino también uno de los fundamentos sobre los cuales está organizado constitucionalmente el ejercicio del poder. Además, la predefinición legal constituye una garantía de certeza acerca de cómo se habrán de comportar los tribunales en un caso concreto. Por esta razón, el juzgamiento de una conducta que en el momento de realizada no era punible según el derecho vigente, es, en principio, violatorio de uno de los más importantes pilares del Estado de derecho.

$\mathrm{Al}$ indagar en las razones que llevaron a la humanidad a crear un derecho internacional que autorice la vulneración del principio de legalidad en aras de intereses más altos, históricamente se considera que los crímenes atroces transgreden los "usos de las naciones civilizadas", las "leyes de la humanidad" y las "exigencias de la conciencia pública”. Estas expresiones de la cláusula Martens, al referenciar conceptos jurídicos indeterminados como civilización o conciencia pública, más cercanos a la moral que al derecho, evidencian un fuerte arraigo del derecho natural y, lo que es más problemático, una puerta abierta a la utilización ideológica o política a conveniencia. Sin la intención de caer en una suerte de relativismo moral, lo cierto es que este híbrido entre derecho y política que supone el derecho de gentes explica muy bien que los juicios penales adelantados ex post facto a lo largo de la historia hayan justificado la violación del principio de legalidad con razones de conveniencia política o, dicho de otra forma, situando al Estado muy por encima del individuo.

Basta con observar cómo se adelantaron los Juicios de Núremberg, en una suerte de juicio de los vencedores a los vencidos en los que, entre otras cosas, se cubrieron con un manto de impunidad los crímenes de las potencias aliadas y se desplazó la culpa hacia la Alemania nazi. En palabras de Teitel, la justicia transicional subyacente en estos procesos "se usó como norma para distinguir entre intervenciones militares justificadas e injustificadas" (2003, pp. 69-94). Por otra parte, el hecho de que muchas de las conductas desplegadas por el ejército alemán no eran punibles según sus leyes, planteó serios inconvenientes a los jueces, que debieron crear 
tipos penales específicos para castigar estas conductas, en abierta violación del principio de legalidad. También se presentaron irregularidades con respecto a la aducción de la prueba, a la recepción de testimonios, entre otras, lo cual pone en duda la legitimidad de los juicios. Así visto, el antecedente más significativo de la justicia penal internacional dejó una huella cuestionable que los demás tribunales ad hoc no superaron del todo, al menos hasta la entrada en vigencia del Estatuto de Roma, que sí previó la legalidad dentro de los principios generales del derecho.

Ahora bien, la investigación y el juzgamiento de los crímenes de lesa humanidad cometidos en Colombia por distintos actores durante décadas es una cuestión que tiene rasgos propios y soluciones que oscilan entre lo local y lo internacional. Desde el punto de vista político, los juicios cuentan con cierta legitimidad, pues existe un consenso más o menos generalizado en la población civil sobre la necesidad de hacer frente a estos crímenes desde el aparato judicial. En una perspectiva jurídica, son ciertos los conflictos entre la legislación nacional y el derecho internacional en los procesos internos: en lo relativo al principio de legalidad, se han imputado tipos penales que no figuraban en la ley en el momento de cometerse los ilícitos, se han aplicado híbridos de normas vigentes y derogadas, y se han impuesto sanciones penales en una operación retroactiva; en lo tocante a la prescripción, conductas que ya habían prescrito según la legislación vigente en el momento de realizadas se juzgaron en virtud de la imprescriptibilidad que predica el derecho internacional.

Hemos reseñado, hasta ahora, dos casos colombianos que hacen patentes estas tensiones: el del coronel retirado Plazas Vega, condenado por desaparición forzada, y el de la masacre de Segovia, calificada de genocidio contra un grupo político. En el caso de Plazas Vega, que juzga en el año 2010 hechos ocurridos en 1985, se adjudica el tipo penal de desaparición forzada aun cuando esta conducta no estaba tipificada en la época, en el entendido de que se trata de un delito de carácter continuado, es decir, que se consuma sucesivamente mientras se desconozca el paradero de las víctimas. A pesar de que esta consideración está sustentada en la jurisprudencia de los tribunales nacionales y de la Corte Interamericana, no deja de ser problemática la cuestión de si puede tornarse desaparición forzada una conducta que empezó a investigarse como secuestro. Y si se aceptara que la entrada en vigencia de una ley sustantiva autorizara esta conversión, ¿podría predicarse lo mismo de las normas procesales? Por otra parte, la aplicación de la Convención sobre la imprescriptibilidad de los crímenes de guerra y de los crímenes de lesa humanidad, que no fue ratificada por Colombia y por lo tanto se incorporó en la sentencia por vía del ius cogens, ¿̇no implicó la vulneración del derecho del procesado a ser juzgado en un 
plazo razonable? Aunque en lo esencial se comparte el sentido del fallo, lo cierto es que la superación de estos inconvenientes, o al menos su exposición honesta, permitiría una justicia más eficiente y garantista.

El segundo de los casos reseñados es el de la masacre de Segovia, ocurrida en 1988 y calificada de genocidio político, a pesar de que la proscripción de esta conducta en Colombia no entró en vigor sino hasta el año 2000. Este caso es aún más difícil que el del coronel retirado, debido a que el genocidio no es un delito de ejecución permanente, como la desaparición forzada. A pesar de que la conducta debió calificarse como homicidio agravado según el Decreto 100 de 1980, la Corte Suprema consideró que se trataba de un genocidio por las particularidades del caso: la intención de exterminio y los destinatarios de la conducta. Para ello, en ausencia de toda norma interna, aplicó la Convención para la prevención y la sanción del delito de genocidio de 1948, que el legislador colombiano había ratificado en 1959. Esta operación jurídica, aprobada en virtud de la primacía del derecho internacional convencional sobre el derecho interno, deja sin embargo la duda de cuál es la pena aplicable, pues la Convención de 1948 no dice nada al respecto. La solución de los magistrados a este horror vacui fue penar al responsable en virtud de la Ley 599 de 2000, esto es, aplicar retroactivamente la ley. Las normas procesales también fueron aplicadas de esta forma, a pesar de no existir justificación para ello en el derecho internacional. Finalmente, dado que esta masacre se inscribió en la serie de asesinatos de los miembros del partido político Unión Patriótica en la década de los ochenta, considerados en conjunto como genocidio por la opinión pública, su denominación como genocidio tuvo algo de decisión política.

Estas son apenas dos muestras de la manera como se juzgan los crímenes de lesa humanidad en Colombia y, sobre todo, de cómo se encaran las tensiones jurídicas inherentes a este proceso de persecución. El escenario es interesante porque permite ver que los jueces de la República están prestando atención a los parámetros internacionales para el juzgamiento de estos delitos y, al mismo tiempo, muestran cierto recato con respecto a los derechos y garantías de los procesados. Pero en atención a la doctrina universalista que apoya la retroactividad de la ley para estos casos y la imprescriptibilidad de ciertos crímenes, los operadores judiciales han tomado partido casi unánimemente por el derecho de gentes.

Acaso no es exagerado afirmar que los jueces del país se rindieron pasivamente a lo que Orozco llama la "nueva conciencia humanitaria": un movimiento formidable por la defensa de los derechos humanos, la protección de las víctimas y el castigo irrestricto de los criminales, que hunde sus raíces en la experiencia de 
Núremberg y cuya nota característica es el primado del derecho sobre la política, de la justicia sobre la paz y de la memoria sobre el olvido (2005). Pero tal vez no deberían olvidar que cada Estado tiene el derecho de juzgar a sus ciudadanos como mejor le parezca, que la retribución no es un imperativo absoluto y que tan importantes como los deberes de la agenda internacional, o quizá más, son los derechos humanos.

\section{Referencias}

\section{A. Legislación nacional}

Constitución Política de Colombia (1991, julio 6). Adoptada por la Asamblea Nacional Constituyente. Gaceta Constitucional, 116.

Decreto 100 (1980, febrero 20). Por el cual se expide el Nuevo Código Penal. Diario Oficial 35.461.

Ley 589 (2000, julio 7). Por medio de la cual se tipifica el genocidio, la desaparición forzada, el

desplazamiento forzado y la tortura; y se dictan otras disposiciones. Diario Oficial 44.073.

Ley 599 (2000, julio 24). Por la cual se expide el Código Penal. Diario Oficial 44.097.

Ley 600 (2000, julio 24). Por la cual se expide el Código de Procedimiento Penal. Diario

Oficial 44.097.

Ley 733 (2002, enero 31). Diario Oficial 44.693.

Ley 890 (2004, julio 7). Por la cual se modifica y adiciona el Código Penal. Diario Oficial 45.602 .

Ley 906 (2004, agosto 31). Por la cual se expide el Código de Procedimiento Penal. Diario Oficial 45.657.

Ley 1312 (2009, julio 9). Por medio de la cual se reforma la Ley 906 de 2004 en lo relacionado con el principio de oportunidad. Diario Oficial 47.405.

\section{B. Normativa internacional}

\section{Derecho internacional humanitario}

Convenio I de Ginebra para aliviar la suerte que corren los heridos y los enfermos de las Fuerzas Armadas en campaña (1949, agosto 12). Ginebra: aprobado el 12 de agosto de 
1949 por la Conferencia Diplomática para Elaborar Convenios Internacionales destinados a proteger a las víctimas de la guerra y entrados en vigor el 21 de octubre de 1950.

Convenio II de Ginebra para aliviar la suerte que corren los heridos, los enfermos y los náufragos de las Fuerzas Armadas en el mar (1949, agosto 12). Ginebra: aprobado el 12 de agosto de 1949 por la Conferencia Diplomática para Elaborar Convenios Internacionales destinados a proteger a las víctimas de la guerra y entrado en vigor el 21 de octubre de 1950.

Convenio II de La Haya relativo a las leyes y usos de la guerra terrestre (1899, julio 29). La Haya: en un solo ejemplar, que quedará depositado en los archivos del Gobierno de los Países Bajos, y del cual se enviará, por la vía diplomática, copia certificada a las Potencias signatarias.

Convenio III de Ginebra relativo al trato debido a los prisioneros de guerra (1949, agosto 12). Ginebra: aprobado el 12 de agosto de 1949 por la Conferencia Diplomática para Elaborar Convenios Internacionales destinados a proteger a las víctimas de la guerra y entrado en vigor el 21 de octubre de 1950.

Convenio IV de Ginebra relativo a la protección debida a las personas civiles en tiempo de guerra (1949, agosto 12). Ginebra: aprobado el 12 de agosto de 1949 por la Conferencia Diplomática para Elaborar Convenios Internacionales destinados a proteger a las víctimas de la guerra y entrado en vigor el 21 de octubre de 1950.

Convenio IV de La Haya relativo a las leyes y costumbres de la guerra terrestre (1907, octubre 18). La Haya: en ejemplar único que queda depositado en los archivos del Gobierno de los Países Bajos, y del cual se enviarán por la vía diplomática copias conformes certificadas a las potencias que hayan sido invitadas a la Segunda Conferencia de la Paz.

Protocolo I adicional a los Convenios de Ginebra del 12 de agosto de 1949 relativo a la protección de las víctimas de los conflictos armados internacionales (1977, junio 8). Conferencia Diplomática sobre la Reafirmación y el Desarrollo Internacional Humanitario Aplicable en los Conflictos Armados, entrado en vigor el 7 de diciembre de 1978 de acuerdo con el artículo 95, y aprobado en Colombia en la Ley 11 de 1992.

Protocolo II adicional a los Convenios de Ginebra del 12 de agosto de 1949 relativo a la protección de las víctimas de los conflictos armados sin carácter internacional (1977, junio 8). Conferencia Diplomática sobre la Reafirmación y el Desarrollo Internacional Humanitario Aplicable en los Conflictos Armados, entrado en vigor el 7 de diciembre de 1978 de acuerdo con el artículo 95, y aprobado en Colombia en la Ley 171 de 1994. 


\section{Derecho penal internacional}

Convención Europea sobre la imprescriptibilidad de los crímenes contra la humanidad y de los crímenes de guerra (1974, enero 25). Adoptada por los Estados miembros del Consejo de Europa y entrada en vigor el 27 de junio de 2003.

Convención para la prevención y la sanción del delito de genocidio (1948, diciembre 9). Adoptada por la Asamblea General de Naciones Unidas en su Resolución 260A (III), entrada en vigor el 12 de enero de 1951 de conformidad con su artículo XIII.

Convención sobre la imprescriptibilidad de los crímenes de guerra y de los crímenes de lesa humanidad (1968, noviembre 26). Adoptada y abierta a la firma, ratificación y adhesión por la Asamblea General de Naciones Unidas en su Resolución 2391 (XXIII) y entrada en vigor el 11 de noviembre de 1970 de conformidad con su artículo VIII.

Elementos de los Crímenes de la Corte Penal Internacional (2000). Nueva York: Informe de la Comisión Preparatoria de la Corte Penal Internacional, suscrito del 13 a 31 de marzo y del 12 al 30 de junio. U.N. Doc. PCNICC/2000/1/Add.2 (2000).

Estatuto del Tribunal Internacional para juzgar a los presuntos responsables de graves violaciones del Derecho Internacional Humanitario cometidas en el territorio de la exYugoslavia a partir de 1991 (1993, mayo 25). Aprobado por el Consejo de Seguridad de las Naciones Unidas en virtud del Capítulo VII de la Carta de las Naciones Unidas, adoptado en su Resolución 827.

Estatuto del Tribunal Militar Internacional de Núremberg (1945, octubre 6). Berlín: Adoptado por el gobierno de los Estados Unidos de América, el gobierno provisional de la República Francesa, el gobierno del Reino Unido de Gran Bretaña e Irlanda del Norte y el gobierno de la Unión de Repúblicas Socialistas Soviéticas, en nombre de las Naciones Unidas.

Estatuto de la Corte Penal Internacional (1998, julio 17). Roma, Italia: Aprobado en el marco de la Conferencia Diplomática de Plenipotenciarios de las Naciones Unidas sobre el establecimiento de una Corte Penal Internacional.

Principios de Derecho Internacional reconocidos por el Estatuto y por las sentencias del Tribunal de Núremberg (1950, diciembre 31). Aprobados por la Comisión de Derecho Internacional de Naciones Unidas y presentados a la Asamblea General de Naciones Unidas.

Principios de Princeton sobre la Jurisdicción Universal (2001, diciembre 4). Informe presentado al Secretario General de Naciones Unidas por la Misión Permanente del Canadá y la Misión Permanente del Reino de los Países Bajos ante las Naciones Unidas, aprobado 
por la Asamblea General de Naciones Unidas en su Resolución 56/677 durante su 56º periodo de sesiones.

Proyecto de Código de crímenes contra la paz y la seguridad de la Humanidad (1996). Informe aprobado por la Comisión de Derecho Internacional de las Naciones Unidas en su $48^{\circ}$ periodo de sesiones, celebrado entre el 6 de mayo y 26 de julio, presentado a la Asamblea General de Naciones Unidas y aprobado por esta en su Resolución 51/10, del $50^{\circ}$ periodo de sesiones.

Proyecto de Código de delitos contra la paz y la seguridad de la Humanidad (1954). Texto aprobado por la Comisión de Derecho Internacional de las Naciones Unidas en su $6^{\circ}$ periodo de sesiones y presentado a la Asamblea General de Naciones Unidas como parte del informe de la Comisión sobre la labor realizada en dicho periodo de sesiones.

\section{Derecho internacional de los derechos humanos}

Carta Africana sobre los Derechos Humanos y de los Pueblos (1981, julio 27). Nairobi, Kenia: aprobada durante la XVIII Asamblea de Jefes de Estado y Gobierno de la Organización de la Unidad Africana.

Carta de los Derechos Fundamentales de la Unión Europea (2000, diciembre 7). Niza, Italia: dictada por el Parlamento, el Consejo y la Comisión Europeos.

Convención Americana sobre Derechos Humanos (1969, noviembre 22). San José, Costa Rica: suscrita por la Secretaría General de la Organización de Estados Americanos en la Conferencia Especializada Interamericana sobre Derechos Humanos, entrada en vigor el 18 de julio de 1978 conforme a su artículo 74.2, aprobada en Colombia mediante Ley 16 de 1972 y depositado el respectivo instrumento de ratificación el 31 de julio de 1973.

Convención de Viena sobre el derecho de los tratados (1969, mayo 23). Viena, Austria: otorgada por la Asamblea General de las Naciones Unidas, entrada en vigencia el 27 de enero de 1980 y aprobada en Colombia mediante Ley 32 de 1985.

Convención Interamericana sobre desaparición forzada de personas (1994, junio 9). Belém do Pará, Brasil: adoptada por la Asamblea General de la Organización de Estados Americanos, en su vigésimo cuarto periodo de sesiones, entrada en vigor el 28 de marzo de 1996 conforme a su artículo XX y aprobada en Colombia mediante Ley 707 de 2001.

Convención sobre los Derechos del Niño (1989, noviembre 20). Adoptada y abierta a la firma, ratificación y adhesión por la Asamblea General de Naciones Unidas en su Resolución 44/25, entrada en vigor el 2 de septiembre de 1990 de conformidad con su artículo 49 y aprobada en Colombia mediante Ley 12 de 1991. 
Convenio Europeo para la Protección de los Derechos Humanos y de las Libertades Fundamentales (1950, noviembre 4). Roma: adoptado por los Estados miembros del Consejo de Europa, modificado por el Protocolo n. 11 (STE n. ${ }^{\circ}$ 155), entrado en vigor el 1 de noviembre de 1998.

Declaración Universal de Derechos Humanos (1948, diciembre 10). Adoptada y proclamada por la Asamblea General de Naciones Unidas en su Resolución 217A (III).

Pacto Internacional de Derechos Civiles y Políticos (1966, diciembre 16). Adoptado y abierto a la firma, ratificación y adhesión por la Asamblea General de Naciones Unidas en su Resolución 2200A (XXI), entrado en vigor el 23 de marzo de 1976 de conformidad con su artículo 49 y aprobado en Colombia mediante Ley 74 de 1968.

\section{Jurisprudencia internacional}

\section{Corte Interamericana de Derechos Humanos}

Corte Interamericana de Derechos Humanos (2006a, septiembre 26). Sentencia C-154. Caso Almonacid Arellano y otros vs. Chile.

Corte Interamericana de Derechos Humanos (2006b, noviembre 29). Sentencia C-162. Caso La Cantuta vs. Perú.

Corte Interamericana de Derechos Humanos (2010, mayo 26). Sentencia C-213. Caso Manuel Cepeda Vargas vs. Colombia.

\section{Libros y publicaciones}

Meron, T. (1998). War crimes law comes of age: Essays. Oxford: Oxford University Press.

O'Donnell, D. (2004). Derecho internacional de los derechos humanos. Normativa, jurisprudencia $y$ doctrina de los sistemas universal e interamericano. Bogotá: Oficina en Colombia del Alto Comisionado de las Naciones Unidas para los Derechos Humanos.

Organización de las Naciones Unidas (1985). Informe del Relator Especial sobre Genocidio, E/CN.4/Sub.2/1985/6.

Orozco Abad, I. (2005). Sobre los límites de la conciencia humanitaria. Dilemas de la paz y la justicia en América Latina. Bogotá: Universidad de los Andes, Temis.

Orozco Abad, I. (2009). Justicia transicional en tiempos del deber de memoria. Bogotá: Universidad de los Andes, Temis. 
Osiel, M. J. (2005). Respuestas estatales a las atrocidades masivas. En Rettberg, Angelika (ed.). Entre el perdón y el paredón. Preguntas y dilemas de la justicia transicional. Bogotá: Centro de Estudios Socioculturales e Internacionales, Universidad de los Andes.

\section{Artículos de revista y páginas web}

Bariffi, F. J. (2009). Jurisdicción universal sobre crímenes de guerra: evolución histórica y su codificación en el derecho de Ginebra. Revista Electrónica de Estudios Internacionales, (17). Madrid: Asociación Española de Profesores de Derecho Internacional y Relaciones Internacionales. Recuperado de [http://www.reei.org/reei17/doc/articulos/articulo_BARIFFI_FranciscoJ.pdf], 2 de junio de 2010.

Bassiouni, C. (2010, junio 5). Jurisdicción universal para crimenes internacionales: perspectivas bistóricas y práctica contemporánea. Universidad de Chile. Recuperado de http://www. cdh.uchile.cl/Libros/18ensayos/ Bassiouni_JurisdiccionUniversal.pdf

Teitel, R. (2003). Transitional Justice Genealogy. Harvard Human Rights Journal, p. 16. Cambridge. 